\title{
Integrated, Multi-disciplinary Approaches for Micro-Manufacturing Research, and New Opportunities and Challenges to Micro-Manufacturing
}

\author{
Yi Qin* \\ Centre for Precision Manufacturing \\ Department of Design, Manufacture and Engineering Management \\ The University of Strathclyde, 75 Montrose Street, Glasgow, G1 1XJ, UK \\ *Email: qin.yi@strath.ac.uk
}

\begin{abstract}
Increased demands on micro-products and miniaturised systems/devices have been a main driver to the rapid growth of the interest in research in micro- and nano-manufacturing. Currently, micro-manufacturing research is bridging "nano-manufacturing" and "macro-manufacturing" and hence, helping to bring nano-technology into real-world and affordable products, for which it is developing multi-length scale and multi-materials manufacturing capabilities. It is also playing more roles in helping transforming traditional industry and products to more competitive ones. Nevertheless, being shifted from "process focus" to "market/product" driven research and technological developments addressing production capability, product quality, pilot production line demonstration and delivery, there is clearly a need for micro-manufacturing research to adopt integrated, multi-disciplinary approaches to address development-related issues concurrently in order to shorten the development cycles for product realisation. It is believed that to transfer laboratory-processes to industrial applications within much shorter time-scales, the associated issues should be addressed with collaborations among different, relevant disciplines. EU funded integrated projects demonstrate such efforts. Product-development-centred approaches brought in expertise and resources in product design, material, analysis, testing, tools, machines, automation and manufacturing system integration as well as life-cycle engineering to address the development needs. At the same time, due to ever updated interests in new products and enabling manufacturing technologies with a view to meeting increased demands from healthcare, on quality of life, for wealth creation, social engagement and sustainable development, there are new challenges to micro- and nano-manufacturing research, which also suggest tremendous opportunities.
\end{abstract}

Keywords: Micro-Manufacturing, Nano-manufacturing, Micro-products, High-value added manufacturing, Research and Technological Development (RTD)

\section{Introduction}

At the present time, "Micro-manufacturing" refers mostly to the manufacturing of Non-MEMS and Non-Siliconematerials. A comprehesive assessment of micro-manufacturing research was conducted initially by a WTEC Panel on "International Assessment of Research and Development in Micromanufacturign" [1] more than 10 years ago, which showed the status of worldwide, micro-manufacturing research at that time. Substantial momentum driving the research and applications of micro-manufacturing was generated by the European Commission through the funding of several large-scale 'flagship' projects in micro-manufacturing in Europe, through its Sixth Framework Programme. The research and outcomes from these projects have been widely reported from various sources, e.g. that reported in/from [2-4]. The research effort has been continuing since EU $6^{\text {th }}$ Framework Programme, together with exploitation of the results from these funded projects, which has 
seen sigificant applications and further exploitation taking place in recent years. At the same time, there have been some shifts of the focus of the research recently, such as engagement with industry with a view to setting up pilot lines, integration of the micro-manufacturing with materials research, increased interactions with nanotechnology research, developing hybrid solutions for micro-proudct manufacturing, transforming Additive Manufacturing into a Micro-Manufacturing Technology, etc.

Previously, the research in metal forming in the University of Strathclyde was focused mainly on precision forging, metal extrusion and sheet-metal forming. The interest in micro-forming was developed from the end of 1990s, such as heating-assisted micro-stamping and micro-extrusion. This led to the development of general interest in the field of micro-manufacturing. Its most sigificant effort in micro-manufacturing was successfully secured EU funding of the FP6 flagship, large-scale integrated project called MASMICRO (2004-2008), which was to integrate of the manufacturing systems for the manufacture of miniature/micro-components. Being one of the largest funded EU projects in EU NMP programmes, a multi-disciplinary approach for addressing development needs in micro-forming led to a series of new design and manufacturing solutions dealing with materials, size-effects, handling, inspection, machine designs and manufacturing systems integrations. Further, the University of Strathclyde played technical leading-roles in driving and managing EU FP7 Polytubes Project (2009-2012) developing several micro-shaping processes and modular machines for the manufacture of emerging medical instruments and other micro-devices, and led the EU FP7 Micro-FAST project (2013-2017) developing a new powder-based manufacturing process and corresponding production system for the manufacture of miniature/micro-components with various difficult-to-cut and difficult-to-form materials, such as metal alloys and ceramics. At the same time, we were also involved in several other highprofile manufacturing research projects. Now, the research in the Centre for Precision Manufacturing in the University of Strathclyde covers the fields of materials forming, micro-forming, ultra-precision/micro/nanomachining, ultra-fine grain metals and multiscale modelling of the materials and manufacturing processes.

Tremandous effort had been made in micro-manufacturing research $[5,6]$. At the same time, new trends recently in manufacturing also suggest new challenges and further opportunities for micro-manufacturing research. The paper will initially give an overview of the market needs and sector-driven applications, followed by describing recent developments in research concerning micro-manufacturing methods, processes and equipment, outlining EU funded research initiatives, exampled by the projects such as EU FP6 MASMICRO, EU FP7 POLYTUBES and Micro-FAST project, which is to demonstrate multi-disciplinary approaches and integrated efforts needed for micro-manufacturing research and technological developments, aiming at shortening the development cycles. Issues such as adding product values through micro-manufacturing, relevance to traditional industries, and business related issues, will then be commented upon. Finally, future challenges and opportunities in micro- and nano-manufacturing are forecasted as a personal perspective.

\section{Products and Market Relating to Micro-Manufacturing}

Micro-products are now widely in use [1, 3, 6-9]. Typical micro-products for automotive and aerospace uses include pressure sensors, thermal sensors, temperature sensors, gas sensors, rate sensors, sound sensors, and injection nozzles, and the components include those for electrostatic, magnetic, pneumatic and thermal actuators, motors, valves and gears. There are more than 200 micro actuators and sensors now integrated into a modern automobile. Micro-products also include sensors for mass flow, micro-heat-exchangers, microchemical reactors, tools/moulds for forming/replication, and components include those for miniaturised electronics products such as mobile phones and laptops. Especially, smart phones are the main targeted market for emerging MEMS devices and micro-sensors, such as those for better communication performance, sound quality, visual experience, navigation and environmental sensing. In the medical sector, microfabricated parts span a wide range of implantable applications in various clinical areas. Typical examples are sensors for cardiovascular, micro-machined ceramic packages, implantable devices, and coatings on polymeric or metal micro-parts. Micro- and nano-technology products will also play a significant role in evolving future factory equipment and the production environment, such as miniaturisation of equipment, lightweight machine-structures, monitoring of the state of the equipment, manufacturing automation, human- 
machine interfaces, factory commnuication and safety, etc.

The micro- and nano-product market is currently influenced strongly by the following significant trends:

(i). Emerging markets driven by needs from specifical sectors such as energy, transport, healthcare and consumer electronics, which are closely linked to important societal challenges. There have been targeted deveopments of micro- and nano-manufacturing technology for particular sectors and markets, e.g. that for energy sourcing, conversion, storage, transport and ultilisation which involve, largely, thin-film technologies, ceramic technologies, nano-materials and integration into surfaces and bulk-parts.

(ii). Increased introduction/ultilisation of nano-materials and nano-technology into micro- and miniaturised products and devices which offers unique peroformance and extended life such as that used in new medical devices, implentable components, and micro-electronics products. Realisation of the smart products, that are a popular pursuit currently, inevitably, needs micro/nano-manufacturing technology.

(iii). Disruptive development of manufacturing technologies, which helped/is helping the development of new products: the development of accelerometers has been helped greatly by the development of precision engineering, piezo-technology, bulk micro-machining and surface micro-machining technololgy. It is expected that new development of micro- and nano-manufacturing technologies (continuous and disruptive) will further enable and accelerate technical and commercial breakthroughs in many application areas such as organic photovoltaics, fuel cells, micro-engines, E-cars, and battery technology.

(iv). Development of new battery technology and smart materials and structures is further driving the development of micro- and nano-manufacturing technologies due to which newly emerging products are expected.

(v). Realisation of the manufacturing concepts such as Industry 4.0 and smart manufacturing would inevitably need significant progress in manufacturing facilities, including hardware, such as that for sensor and online-inspection technology and implementation.

(vi). Recent enthusiasm on robotics and autonomous devices is also influencing the development of micro/nano-technology products.

(vi). Shortened developent time, compared to what happened 20 years ago. Currently, from concept, through research and development, to the diffusion of the product into the market, the time has been shortened considerably. It is expected that the development time will be even shorter, considering the multidisciplinary collaborations and integrated project approaches are being currently utilised in micromanufacturing research and technological development as well as the industrial leadership implemented.

There is no accurate data on the current market on micro-products and the forecast for the future market varies from different sources. According to Yole's early forecast [9], in terms of MEMS, a significant volume growth was foreseen (around 20\% expected between 2013 - 2019). According to the iSuppli 2011 report [3], the micro-products' CAGR (Compound Annual Growth Rate) for between 2011 and 2016 should be over 20\%. Although it is difficult to predict an exact scale of the future market for micro- and nano-technology products, it is very promising, according to the demands of current customers. The functionalities and manufacturing cost will, however, still be key competitive factors, which raise signficant challenges to the development of microand nano-manufacturing technologies to meet the requirements for new functions, low-cost and high-quality products.

\section{Overview of Micro-Manufacturing Research and Technological Developments}

Two types of efforts can still be seen in RTD of micro-manufacturing: continuing development of traditional micro-manufacturing processes such as laser processing, photo-chemical-etching/machining/forming, LIGA, deposition/plating, moudling, etc., and scaling down conventional processes for micro-manufacturing, such as mechnical cutting, metal forming, EDM, ECM, injection moulding and powder metallurgy.

Micro-machining is a relatively mature technology which has seen now wideseprad applications such as manufacture of sensors, accelerometers, actuators, micro-mirrors, fibre-optics connectors and micro-display. Its development benefited significantly from the development of precision engineering and ultra-precision 
machining in 1980s and 1990s, in terms of tools and machines development. Effort is being made to achieve complex 3D, intricate micro-features/components, the maching of difficult-to-cut materials such as metal matrix composites, silicon carbide and ceramics, as well as nano surface patterning [10-14]. Significant efforts have also been devoted to the improvement of the precision of machine tools and the development of errorcompensation methods. Bench-top machine-tool designs have now become a trend showing the design being shifted from large scale, ultra-high precision designs to miniature structures and low-cost system designs. Besides mechanical machining, research and applications of Micro-EDM, Micro-ECM, Photo-ChemcialMachining, Laser Machining, etc. have progressed significantly, especially from 1980s and 1990s [15-16], for making smaller-sized components and features, being largley seen from 2000s, and are now widely used for manufacturing micro-products and tools $[6,17-18]$. These are all mature technologies which have now been incoporated into industrial production.

Over the last 20 years, micro-forming has been researched extensively, due to its potential for higher production-rates, better material integrity, less waste and lower manufacturing costs. Fundamentals such as that relating to material characterisation and size-effects were particularly researched, and scaling down the conventional forming-processes is still dominant. To-date, various micro-forming configurations have been investigated [5, 6, 19-24], including: Laser-shock/pulsed/bulging/peening forming and Laser-heating-assisted forming; Micro-cold, -warm, -hot and -isothermal forging; Micro-extrusion and -backward canextrusion/ultrasonic vibration micro-extrusion; Micro-rolling/Roll-to-roll forming/Micro-dimple-forming and incremental forming; Micro-stamping (hard and soft tools)/Micro-deep-drawing/Micro-bending (laser); Microsuperplastic-forming; Micro-cold and hot-embossing (on metals)/Micro/nano-imprinting/Micro-coining; Microhydroforming (tubes); Liquid impact micro-forming, and Semi-solid micro-forming. There have been some good examples of industry applications of micro-forming technologies in individual cases (Germany, China, Japan, UK, USA, South Korea, etc.), and the remaining challenges are still on the micro-tooling, tool life, part quality, forming-limit, inline inspection, and technology standardisation. These affect the introduction of the processes and technologies to real production applications.

LIGA is still an effective technology for precision manufacturing of high-aspect-ratio micro-components and systems, while other replication techniques such as micro-hot-embossing, micro-injection-moulding, microcasting/soft moulding, micro-sintering, are seen as better solutions to the low cost, mass-production of microcomponents/features [25-29], reel-to-reel UV embossing being a good example for mass-production. Micro powder injection molding $(\mu \mathrm{PIM})$ is now one of the most important and widely used micro-manufacturing technologies, and it has been researched intensively during the last 10 years. Its development has been helped greatly by large RTD funding, e.g. recently funded EU projects [30]. $\mu$ PIM is a low-cost mass fabrication process for manufacturing microstructures and micro-sized components, with multi-materials capabilities. It has been used for processing many different materials (e.g., ceramics and metals) for very complex geometries. For making small geometries, silicon-mould-inserts may be used, taking advantage of deep reactive ion etching. Nevertheless, the following sintering processes would need to be improved further.

As an additive technique, Electro-forming has been used widely, and already produces micro-components and micro/nano-structures. It is, to-date, still a powerful technique for securing fine-geometry and low-cost production [31]. By combining an electric-chemical method and an etching method, Efab (a system developed by MEMGen, USA) was developed [32]. The method adds layers of from 2 to 20 microns thickness and is able to create 3D metallic features with support of the sacrificial material, which is later etched away. As for rapid manufacturing, manufacturing a micro-part may involve microdeposition, ultrasonic-based micro powderfeeding, dry-powder cladding/sintering, followed by laser micromachining or mechanical finishing. Fabrication of meso- and micro-structured devices by direct-write deposition and laser processing of dry fine powders were made successfully, which was seen to be another effective way to fabricate 3D structures and strucutres even with heterogeneous material compositions, such as that undertaken in EU FP6 Manudirect Project and FP7 Micronano Project. Inkjet technology offers a prospect for the reliable and low-cost manufacture of Flat Panel Displays (FPD). Compared to other conventional processes, an inkjet printing method for colour filters $(C / F)$ in LCD or RGB patterning in OLED offers potential for the mass production of enlarged-display panels 
with low costs while the possibity of depositing nano-particles offers more potential applications and higher quality of products [33-34]. 3D printing of functional, multi-materials micro-parts/devices is, currently, also attracting a lot of interest, such as microfludic devices [35]. Altough a lot of effort have been made in micro-AM (micro additive manufacturing), there are still several key issues to be addressed and needs to be met [36], especially product property integrity and surface finish. Hybrid processes or integration of several processes into a common manufacturing platform are seen to be solutions addressing some key issues relating to the product quality and manuacturing efficiency.

During the last 20 years various bench-top/desk-top machines and miniature manufacturing systems for micromanufacturing have been developed and introduced to industry $[6,17,37]$. The development still attracts significant interest from researchers, and the industry involved has started commercialising the machine designs already, e.g. that for micro-machining, micro-EDM, micro-embossing and micro-injection-moulding. Conventional facilities for manufacturing miniature/micro-products may not be compatible, in sizes, to the products to be made in miniature/micro-manufacturing. It is, therefore, necessary to reduce the scale of the equipment which could, in turn, reduce equipment cost, energy-consumption and material wastes, and create a more-user-friendly production environment. At the same time, as the scales of the machinery and auxiliary equipment are reduced, the mass of the mechanical parts is reduced dramatically and, as a result, the speed of the manufacturing tools could be increased, which could result in increase of the production rates. Another merit is shorter force/energy loops and control loops for small machinery and hence, the precision of the machinery could be increased comprehensively. Micro-machines/micro-factories are typical examples of such facilities. These development address sustainable development issues very well. It actually stimulates new manufacturing strategy and system development philosphy, e.g. large-scale productions may be effected with small scale quipment, e.g. small-scale modular equipment to fulfill the individual production tasks in a largescale production.

Multiple-process equipment is another development attracting a lot of interest. Such equipment is to include various micro-fabrication processes into one machine, such as EDM, ECM, Milling, Grinding, Laser Machining/Heating, and it is an ideal solution to implement various process chains within an integrated platform, which could significantly reduce the number of component handlings during changeover from machine to machine. Another resulting benefit is reduction of the possible accumulation of manufacturing errors. An example is the Hybrid $\mu E D M$ machine made by Mikrotools which is able to perform multiple machining tasks [38]. The majority of the equipment/devices developed in micro-factories or miniature manufacturing systems may not be classified as multi-process equipment/devices, since each of these is a stand-alone machine which deals with a particular process. Collectivelly, a platform integrating multi processmodules can, however, function as a multiple-processes machine or system, which is the case in most of the platforms developed in Europe [30, 39-40]. Currently, due to the latest enthusiasm shown in 3D printing or Micro-Additive-Manufacturing, there have been some new machine concepts proposed, combining 3D printing/AM with micro-machining and micro-forming with a view to achieving higher accuracy of the parts fabricated as well as overall manufacturing efficiency.

Micro-manufacturing technology is still being developed, and quality assurance plays an even more important role in supporting the transition of micro production processes from non-robust to robust and stable processes $[30,41-43]$. Quality assurance faces particular challenges at the production level - some common quality methods for macro-length-scale manufacturing may be difficult or even impossible to be applied/implemented. The need for the development of the technologies and systems for dimensional metrology at different lengthscales and integrating them is evident. European Training Network on "Process Fingerprint for Zero-defect Net-shape MICROMANufacturing" (EU MicroMAN project) [44] aims to train researchers to develop innovative technological solutions for high-quality and high-throughput micro-production by specially looking into the process fingerprint issues concerning defect/error formation and netshape manufacturing in micromanufacturing process chains.

\section{EU Funded Research Initiatives Towards Industrial Applications}


The EC's effort in funding micro- and nano-manufacturing research has been tremandous and this is evident in the EU FP6, FP7 and Horizon 2020 programmes. In FP6, there were several large projects funded in the field of micro- and nano-manufacturing [2-4], such as projects MASMICRO, 4M, Launch-Micro, Production4 $\mu$, EUPASS, Hydromel, HYTI, NANOSAFE2, Manudirect, Napolyde, PRONANO, NaPa, CHARPAN, NANOIMPRINT, and NanoCMM. The projects covered areas such as Micro-manufacturing (massmanufacture of micro-products, multi-materials micro-manufacturing technologies and applications, direct manufacturing by laser melting/sintering, and transforming traditional SME industry to micro-manufacturing industry); Precision manufacturing (ultra-precision machining and assembly systems, hybrid ultra precision manufacturing process based on positional- and self-assembly, direct ultra-precision manufacturing); Nanomanufacturing (safe production and use of nanomaterials, nano-structured polymer deposition processes for mass production, nanopatterning, production of parallel intelligent cantilevers, and charged particle nanotechnologies); and metrology for micro- and nano-manufacturing. These efforts enabled the EU to ensure its leading position in these individual areas.

In FP7, besides the projects which were completed early, such as POLYGLASS, MULTILAYER, NANOMICRO, MIDEMMA, FLEXPAET, INTEG-MICRO, $\mu E C M$, POLYTUBES, PLAST4FUTURE, SONO"R"US project, within the FoF initiative ("Factory of the Future"), a group of new projects were also executed recently in the field of micro-manufacturing [30] which supported the effort of meeting challenges of maintaining high-quality manufacturing in Europe. These projects were working in synergy and created, under the support of European Commission, a "cluster of the micro-manufacturing industrial research", characterised by common development objectives, complementary technologies and industrial sectors: HiPr project developed a novel approach for metal 3D micro-parts production, capable of reducing finishing operations to help bringing the research into the forming of small parts into industry applications; 3D-HiPMAS project demonstrated pilot line fabrication of advanced MID-based micro assemblies; Smartlam project built on a layer by layer lamination of functionalised film sheets with different material properties, allowing for the manufacturing of small to medium series of micro components in a rapid manufacturing manner; Hi-Micro project intended to realise an innovative approach for the design, manufacture and quality control of tool inserts, through further developing tooling technologies for micro-injection (powder) moulding $(\mu \mathrm{IM})$; HINMICO project developed and optimised manufacturing processes to produce high quality multi-material microcomponents, with a possibility of additional functionalities; Micro-FAST project developed a completely new manufacturing system for the volume production of miniaturised components by overcoming challenges in manufacturing with difficult-to-process materials; FaBiMed project dealt with flexible and cost-effective tooling fabrication, precision replication technologies and advanced inspection techniques; and MICROAB is a project dealing with micro-machining with abrasive waterjets. The outcomes of these projects have taken Europe's micro-manufacturing research and applications to a new level.

In EU Horizon 2020, several projects in the field of micro-manufacturing have also been funded: e.g. UItraSURFACE project develops ultra dynamic optical systems for high throughput laser surface processing; NextFactory project delivers an all-in-one manufacturing platform for system in package and micromechatronic systems; R2R Biofluidics project develops large-scale micro- and nano-fabrication technologies for bioanalytical devices based on roll-to-roll imprinting; TOP HIT project develops micro-Transfer-Printing (TP) technology by which essential materials or devices, with thicknesses of a few microns, are separated from their native substrates and then transferred in parallel to the new platform according to the desired positioning while maintaining micron-scale placement accuracy [45].

\section{Integrated, Multi-disciplinary Approaches for Micro-Manufacturing Research and Technological Developments}

The following three case-studies are to show integrated, multi-disciplinary approaches to address development needs in micro-manufacturing, with forming/shaping as core-technologies. It is believed that to transfer laboratory-processes to industrial applications within much shorter time-scales, all associated issues should be 
addressed concurrently, i.e. key aspects relating to product developments would have to be addressed concurrently and the development addressing the manufacturing process alone will have limited impact as well as resulted in a long product development cycle. Product-centred approaches bringing in expertise and resources in product design, material, analysis, testing, tools, machines, automation and manufacturing system integration as well as life-cycle engineering are what used in the following projects.

\subsection{EU FP6 MASMICRO Project (2004-2008)}

Previous research in micro forming was largely focused on fundamental issues with a view to developing undertanding of process principles, studying material and tool behaviours, with intensive effort on the investigation of size-effects in microf-orming. While the studies were based largely on the laboroatoy processes and equipment, applications of micro-forming technologies were hampered largely by lack of mass production facilities, high-quality tooling, sutiable materials and robust analysis tools. Lack of effect integration with other manufacutring processes was also identified to be one of the key weaknesses. These were main considerations bind the project idea.

The project was one of the largest EU projects ever funded for conducting research in micro-manufacturing, and a good example of applying a multidisciplinary and research integration approach to problem-solving for micro-manufacturing [5]. It was an integrated project (the first of this kind in EC funded research) consisting of 8 subprojects (Fig. 1), assembling experts from 10 different disciplines and 36 partners from 13 EU countries. The project assembled partners who completed process and supply chains.

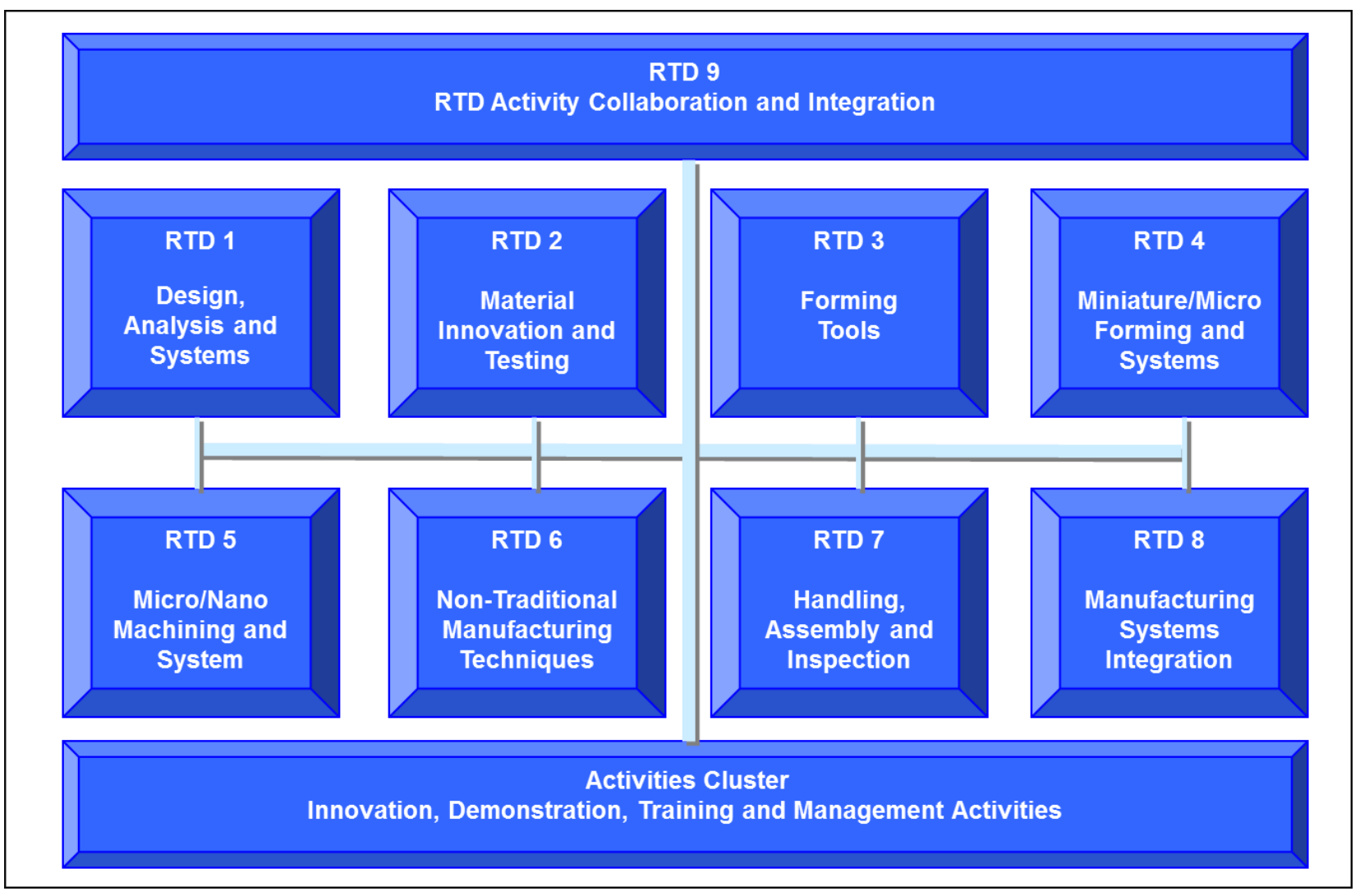

Fig. 1 MASMICRO project structure and main activities

The project intended to develop a series of methods, techniques and manufacturing facilities for the mass production of micro-compoenents, and addressed three apects of the development needs: development of mass production processes based on micro-forming and micro-mechanical machining; development of miniature/bench-top equipment to bridge gaps between costly large-scale systems and micro-machines; and the application of ultra-precision techniques to improve the precision of previous miniature/micro-machine designs. 
By the end of the project, it generated 135 publications, 13 patents, 4 spin-off companies and 48 exploitable results. The industrial technologies and new facilities developed included new laser systems for micro-material processing, photo-electro-forming and LIGA techniques, new surface-coating techniques, micro-tooling techniques, precision-handling devices (robotic system and filtering system), micro-actuating materials and devices, a micro-sheet-forming machine, a micro-extrusion machine, a micro-hydroforming machine and a micro/nano-cutting machine, and a manufacturing execution system (MES) (Figs. 2 and 3). Fig. 4 illustrates the subsystems and the scheme of the integration through the Manufacturing Execution System develped.

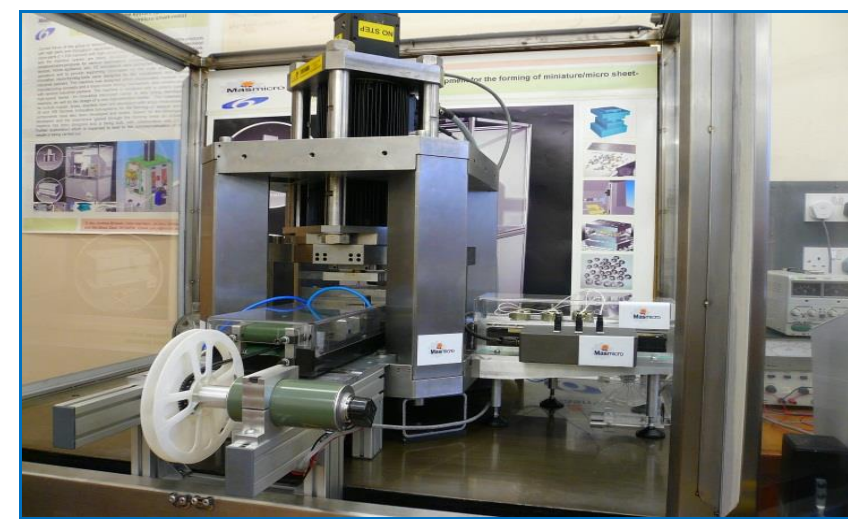

Fig. 2 Micro-sheet-forming machine system (The University of Strathclyde)

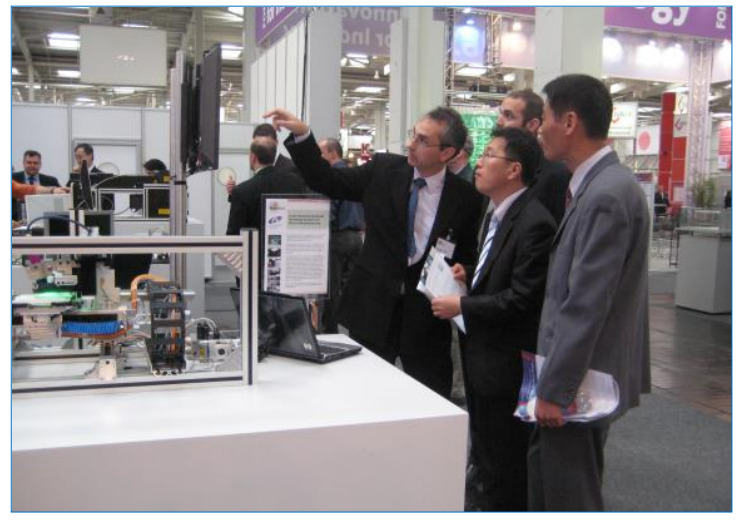

Fig. 3 MASMICRO project manufacturing facilities and demonstrators exhibited at Hannover Messe, 2008

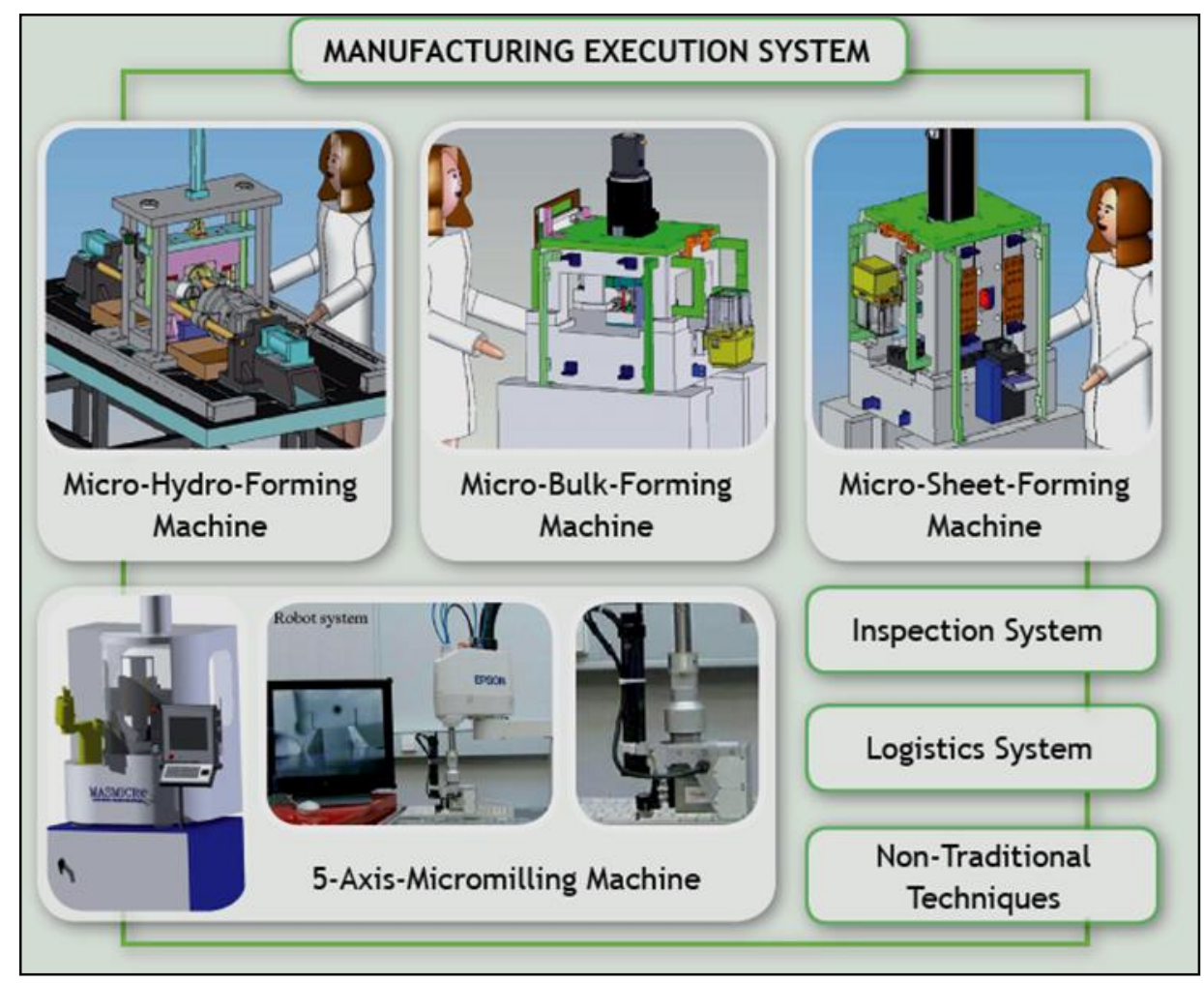

Fig. 4 Illustration of the MASMICRO subsystems and the scheme of the integration through the MES

18 industrial partners participated in the project and some of these had already started implementing the findings during the project whilst others deployed the results after the project. Significant industrial applications have been seen since the end of the project in 2008. For example, Centro de Ingenieria Avanzada de 
Superficies, Spain, a surface engineering company, was awarded two patents concerning surface coating techniques developed through the MASMICRO project, three, new EU and National collaborative R\&D projects, and four new contracted work related to surface engineering in forming-tooling, before 2013, which helped them in expanding their business. The micro-hydroforming machine design was licensed to an industry for production (via the University of Applied Science Cologne, Germany), which helped them in developing a new business in micro forming. Micro-stamping machine has been used to produce various micro-components such as micro-springs and micr-caps and micro-extrusion machine was used for forming a hearing aid component, micro-pins and a dental implant. Based on the outcomes from the MASMICRO project on laserassisted forming/processing, Latronics $\mathrm{GmbH}$, Germany, was able to rapidly expand its business, e.g. new laser-systems were sold to various customers and the applications covered electronics, semiconductors, machine building and tooling sectors. The project also helped Tecan, a leading UK manufacturing company in micro-fabrication, in manufacturing process improvements (Photo-electro-forming and LIGA process for microtooling) which were incorporated into their routine production. As one of the major outcomes of the MASMICRO project, the Manufacturing Execution System (software) was transformed successfully to a company in Germany from which the company was able to create 17 new Jobs. In its first 16 months of the implementation, $30 \%$ of the company's turnover was generated by this product. As one of the associated developments from MASMICRO, Cedrat Technologies, France, started a business on piezo-actuation systems for machining successfully after the project. Pascoe Engineering Ltd, Scotland, one of the key partners in micro-tooling, developed themselves into a showcase tooling industry of Scotland, while the project helped them significantly in improving their tooling capacity, and hence, being able to expand their business into more industry sectors, from previously, electronics-product sector, to a wide range of industrial sectors.

\subsection{EU FP7 POLYTUBES Project (2009-2012)}

Previous effort in micro forming was largely focused on bulk and sheet component-forms and manufacture of tubular micro-components was addressed occasionally with some minor effort, especially focused on the laboraroty processes only. The MASMICRO project addressed forming of tubular micro metal parts by developing micro-hyrdoforming tooling and an industrial machine. At the same time, needs of polymeric micro tubular components in medical and energy sectors were also identified [39-40]. However, producing those components largely relied on manual work or operations with machines with semi-autmated modes only. The facilities available were, typically, for large-size tubes, e.g. in a range of a few to several tens millimetres. A main challenge to the production of polymeric, tubular micro-components also significantly lies on the capability of shaping those tiny, fragile tubes as well as controlling accuracy of the shaped sections.

The POLYTUBES project dealt with manufacturing tubular micro-components for fluidic devices for general applications such as medical analysis, heat management and capillary electrophoresis. It bridged the gaps in manufacturing polymeric tubular micro-components by developing a completed process chain, from product design, raw materials preparation, material-shaping processes, tool-fabrication, modular machines, to the manufacturing system and product validation (Fig. 5) for which three-layer developments were planned: Knowledge-based design for manufacture; Manufacture of polymeric tubes and tubular components; and Assembly, testing, inspection and product validation. 


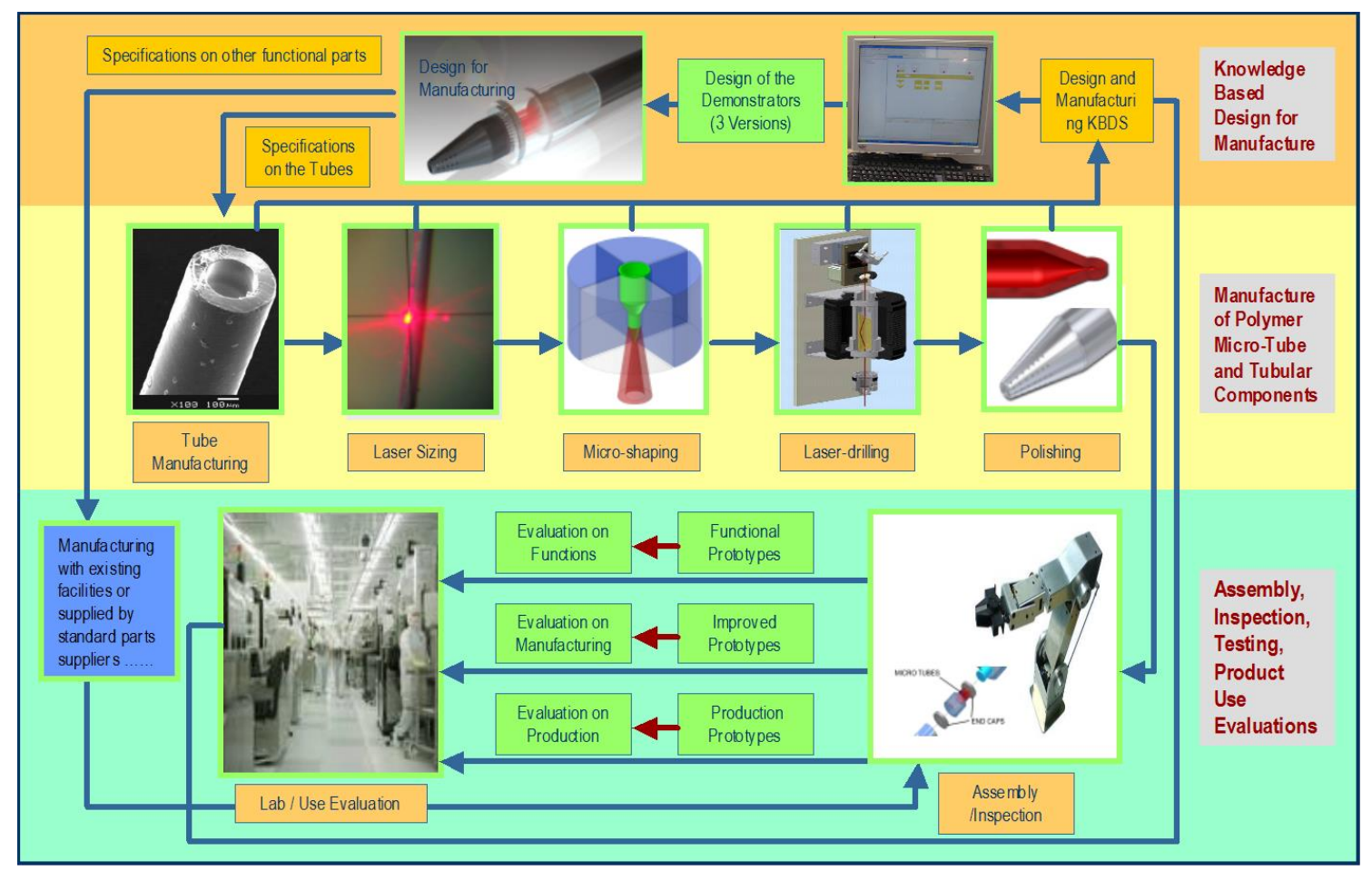

Fig. 5 Project planned developments and methodology utilised

The project consortium consisted of 17 Partners from 9 EU countries, including 10 industrial companies. It developed a common platform to integrate several processes (Micro-rolling, Micro-hot-embossing, Microblow-forming, Laser-drilling/trimming) in a form of integrating individual, modular miniature machines (Fig. 6). The small machines were linked through a global handle system (robotic manipulator), while each of the modular machines had its own inter-handling device that was able to feed the tubes and to pick up the shaped components. In such a way, each modular machine can be a stand-alone machine for different applications but can also be integrated onto a common platform for forming an integrated process chain. Other merits are: high manufacturing flexibility - the process combinations can be programmable, there is high modularity (a highly modular system) and the system can be easily re-configured.

The POLYTUBES project represented a good example of developing miniature manufacturing systems integrating micro/miniature machines onto a common platform for micro-manufacturing.
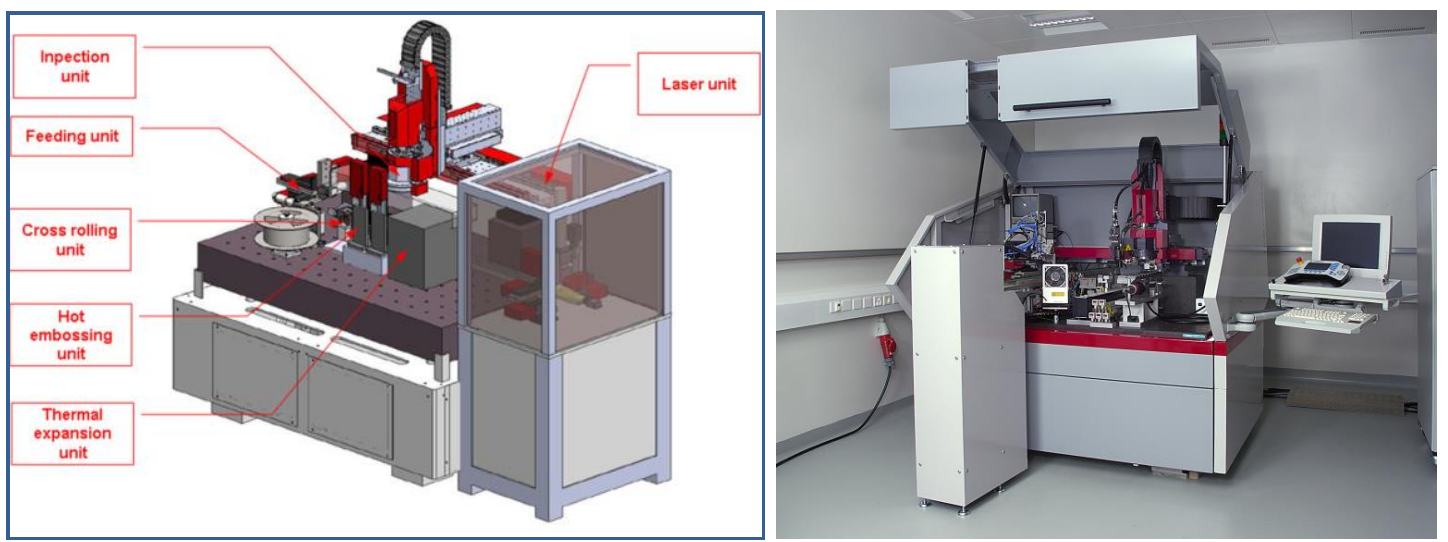

Fig. 6. (a). Graphic illustration of the micro-factory concept; and (b). The manufacturing platform used for testing the concept (POLYTUBES consortium and Sysmelec of Switzerland)

\subsection{EU FP7 Micro-FAST Project (2013 - 2017)}

Although significant efforts were made in micromanufacturing, there are still significant challenges to the 
manufacture of miniature and micro-components to meet the requirements for multi-materials and multifunctionalities while maintaining low manufacturing-cost, especially with difficult-to-cut and difficult-to-deform materials, such as that for components used in chemical-physically aggressive environments, with biocompatible functions, tribo-chemical functions and excellent electrical and magnetic properties, etc., which hinders introduction of innovative tools, components and products into the market, such smart materials and structures as well as high-temperature micro/nano-products. Although the progress in miniaturisation of products and systems will continue in the near future, this progress depends largely on the availability of costeffective and high-quality manufacturing methods for the volume production of multi-materials, highperformance miniature and micro-parts.

Micro injection moulding has been seen as one of the most efficient processes for powder-based manufacturing of miniature/micro-components with multi-materials capabilities, which has been researched intensively recently and widely used in industry. Other processes such as laser-melting/selective sintering, 3D printing, soft-mould moulding, hot-embossing, LIGA and micro-casting, etc. are also good options for microInano-manufacturing with difficult-to-cut and difficult-to-deform materials. However, each of these is of some obvious constraints and limits.

By applying external electrical-field, the electro-plasticity and Joule heat induced in the material by the electric current pave the way to the development novel manufacturing processes, and hence, enabling forming of difficult-to-process materials such as metal alloys and ceramics (Fig. 7). Electric-Field activated sintering technique (FAST) would enable an increase of manufacturing flexibility and high-quality of the components with desired structures and functionalities, with less or no restrictions on the raw-material microstructures, including use of nano-alloys. Nevertheless, existing FAST processes could not be simply scaled down to the manufacture of miniature/micro-components, due to: difficulties of handling powders; strong "size-effects" at the micro-scale; different sintering mechanisms at the micro/nano-scale; lack of design and manufacturing guidance; lack of suitable manufacturing facilities for producing complex shaped components and for highthroughput and cost-efficient production.

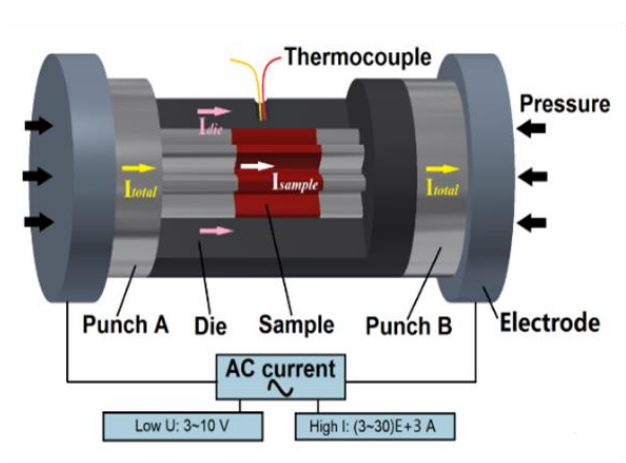

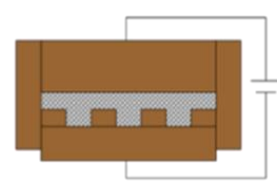

(a)

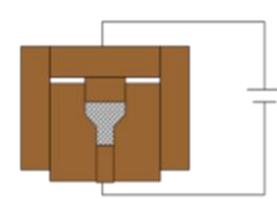

(c)

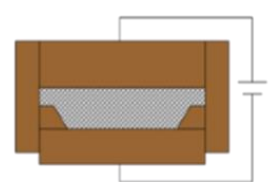

(b)

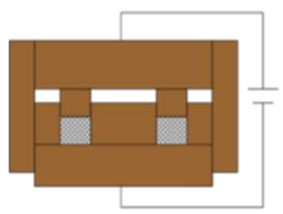

(d)

Fig. 7 Illustration of Micro-FAST process configuration and possible tooling-variations for flexible manufacturing

Micro-FAST is a process concept which scales down conventional FAST to the micro-scale process (dealing with miniature an micro-sized components) and combines the sintering process with a micro-forming process to enable shaping components under coupled multi-fields actions (Fig. 7), and hence, to achieve high-density, near-net-shaped components with high efficiency (Fig. 8). For example, WC-6Co cemented carbides were formed with this technique [47]; MnZn ferrites were also sintered with this method [48]; various 316L stainless steel parts were formed successfully [49] as well as that from copper powder [50]. More microparts formed with and developing process understanding of Micro-FAST were reported in the literatures [29, 51-55]. The main techniques that were developed for overcoming barriers of the traditional FAST for the applications at the micro scale including: (i). Directly feeding loose powders into the dies/moulds (i.e. no need for preparing a 
green compact); (ii). Combining micro-forming (forming the component at the micro-scale) with the FAST to enable complex shapes/features at the micro-scale, being assisted by using large current density; and (iii). Directly forming the component using the shaping dies/moulds without using lubricants.

Comparing to other FAST processes, Micro-FAST process uses significantly large current density $(>100 \sim 400$ $\mathrm{KA} / \mathrm{cm}^{2}$, due to very small heating areas). Due to a small material-volume used, a very high heating rate $\left(>1000^{\circ} \mathrm{C} / \mathrm{s}\right)$ can be achieved, and a high cooling rate $\left(>1000^{\circ} \mathrm{C} / \mathrm{s}\right)$ is also achievable with a dedicated cooling system. Much shorter sintering time also suggests consolidation of nanocomposites into bulk-sized components while also preserving their nanostructures much more easily.

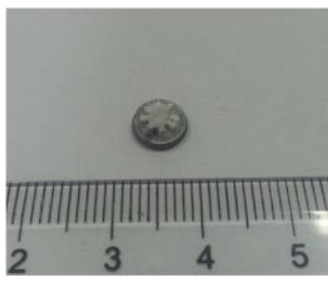

Al2O3 Micro-Gear

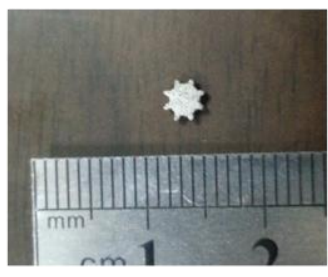

Ti Micro-Gear

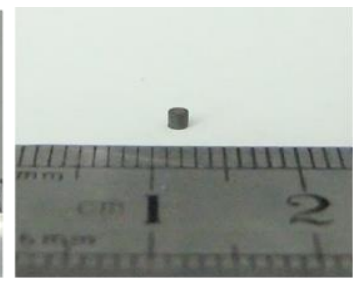

SS Micro-Cylinder

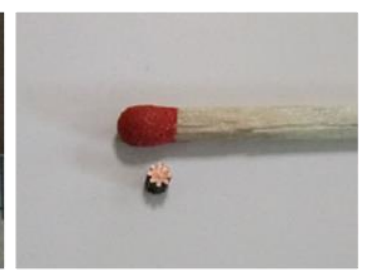

Copper Micro-Gear

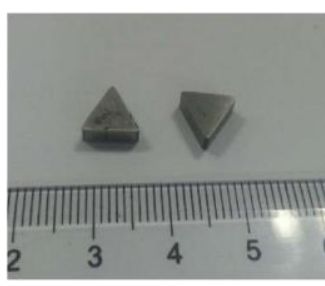

NiTi Parts

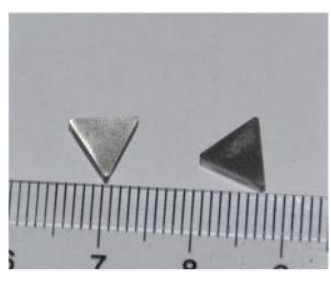

Ti Micro-Cutter

\section{Fig. 8 Photos of the sample parts formed with Micro-FAST [47-54]}

Being encouraged by the achievements in fundamental research and laboratory process developments through internaitonal collaborations between Sichuan University, China, and the University of Strathclyde, UK [29, 47-51], an EU consortium was established with an aim to transfer the laborotory Micro-FAST process to component production by developing high-quality powders and technological enablers for manufacturing (Fig. 9). The EU Micro-FAST consortium assembled various experts and resources from 18 partners from 9 EU countries, including 11 industrial partners to address the development needs respectively in powder materials, powder feeding, tool design and fabrication, machine design and construction, condition monitoring and system automation, tool inspection and automated cleaning, being supported by multi-scale modelling and lifecycle engineering experts and enabling tools.

Micro-FAST project resulted in a completely new manufacturing system for the volume production of miniaturised/micro-components by overcoming the challenges on the manufacturing of these components with a wide range of materials [46] (e.g. metallic alloys, composites and ceramics) [52-55] that are normally seen as "difficult-to-cut" and "difficult-to-deform" materials, through: (i) developing the Micro-FAST laborotory process into a high-throughput, flexible and cost-efficient production process involving simultaneous microforming and electric-feld activated sintering of powder materials; (ii) developing technogical measures for scaling up the process for improved forming quality and efficiency; (iii) developing an automated industrial press system for Micro-FAST based micro-/nano-manufacturing, including fully automated modes for heating, cooling, vacuum, measurement, condition monitoring as well as tool transport. These were enabled/supported by developing: (a). a new press-machine with an innovative handling-system; (b). an innovative inline monitoring and inspection system; (c). innovative multiscale modelling techniques for the analysis of denstifiction and forming processes; (d). new tool-designs and micro-tooling techniques for high-performance tools, and (e). high-quality nano-material systems. The whole development took into account energy savings, cost and waste reduction and material-recycling issues, which were studied thoroughly through an expertise Life-Cycle Assessment. $1^{\text {st }}$ Micro-FAST prototype production machine system has been built, tested and 
demonstrated, and continuing optimisation of the machine system and tool-designs is being carried out, aiming at fully meeting industrial production requirements.

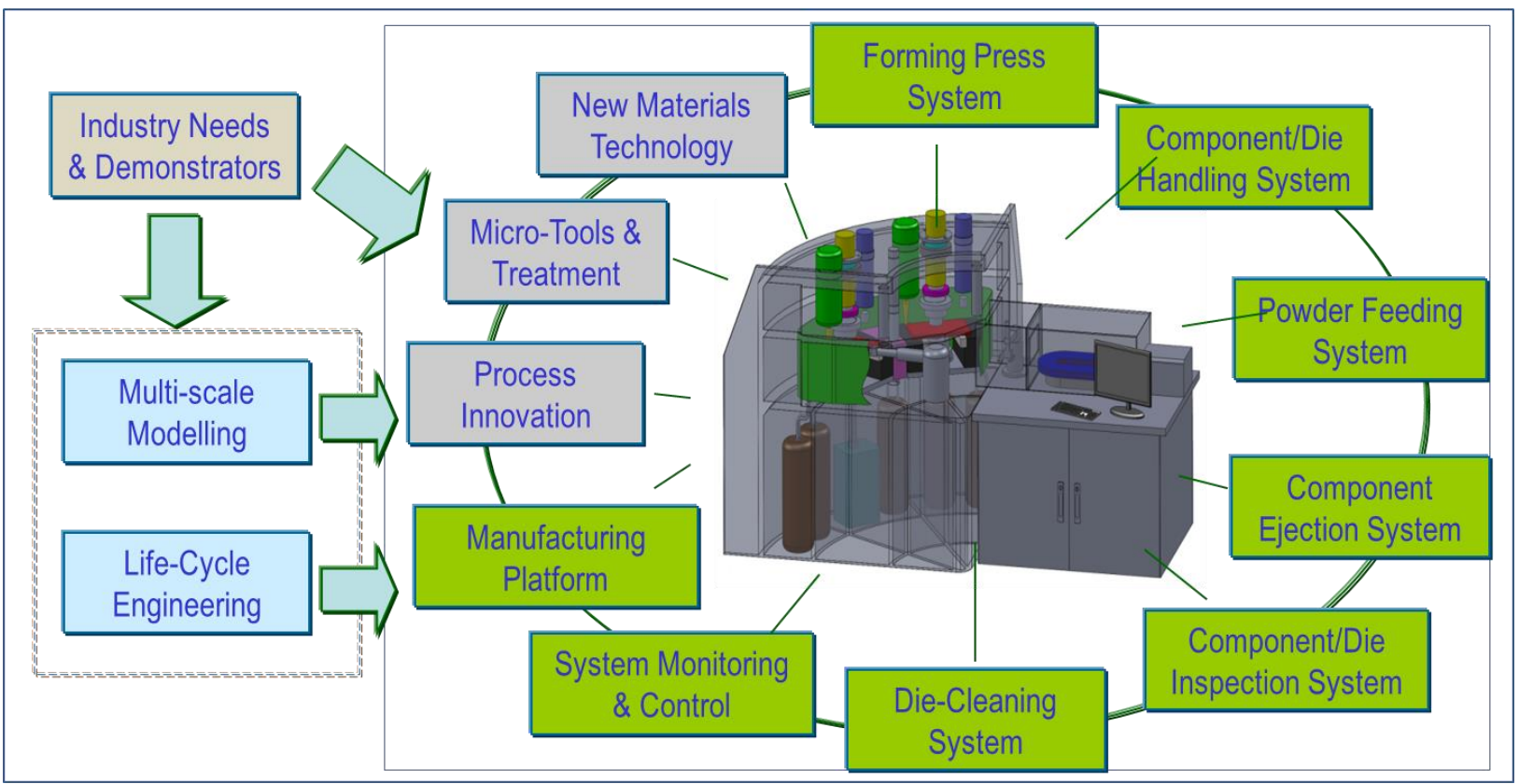

Fig. 9 Illustration of the Micro-FAST project's key developments in relation to the development of the core Micro-FAST production system

\section{Relevances to the Industry's Developments}

During the last 20 years, significant efforts have been made in micro-manufacturing resarch and technological developments for which significant funds have been made available to support such efforts. The gains from industry due to these effort have been evident, being reflected largely by enhanced technological competiveness, increased product innovation, added new job and skills.

\subsection{Adding values to products through Micro-/Nano-manufacturing}

The requirments for micro-manufacturing may be classified into two levels: the component level and the product level (assembly/packaging). Micro-manufacturing technology is being developed not only to meet these manufacturing requirements but also for adding values to the products. For example, to be able to make special metallic and ceramic micro-components for micro-robots and micro-engines, produce high-quality 3D electrical interconnections for 3D micro-assemblies, create micro/nano structured surfaces/parts for batteries and micro fuel-cells, develop special mechanical and mechatronics parts/elements for micro-machines or miniaturised equipment, etc., would itself add values to the associated products.

Considering where/how value could be added to a product through micro-/nano-manufacturing, the following are some observations:

- Improving surface quality through ultra-precision manufacturing (e.g., nano-machining and FIB machining);

- Adding surface functionalities of the component/system surfaces through surface texturing (e.g., micromachining, laser ablation, micro-EDM, micro-ECM, hot-embossing, roll-to-roll forming) and coating/deposition (e.g. multi-layered nano-coating, then-film deposition, laser alloying, etc.);

- Creating new functional structures of the components/systems through micro/nanoforming/raplication/sintering and additive manufacturing (e.g. hollow-sectioned, channelled, functionally graded structures; 3D printed multi-length scales and multi-materials structures);

- Converting low-value materials into high-value products such as nano-materials/nano-composite products (e.g. via micro/nano-forming, casting, sintering and 3D printing for high-quality components);

- Creating value by high-quality assembly from low-value components/materials (e.g. micro-injection 
moulding assembly, high-precision mechanical, micro-joining and self-assembly).

\subsection{Relevance to traditional industries}

The micro-/nano-manufacturing industry may still be small, in terms of sizes, compared to other industries, such as automotive, aerospace, energy and healthcare. However, it can play significant roles in driving other industries to a new level. For example:

- Traditional industry needs breakthrough/transformation/improvement, considering significant competition and demands on the new products and higher quality. Achieving these cannot rely on organisational improvements alone, but also requires, significantly, technological acquisition. Research in micro-/nanomanufacturing is one of the most promising areas that could help to deliver the required technological solutions for product innovations and high-quality production.

- Research in developing new micro-/nano-materials will meet many material challenging issues faced in the traditional materials and manufacturing industry - an area in which many current industries are seeking better solutions for new material-properties and performances.

- Manufacturing-process concepts evolved in micro-/nano-manufacturing research will significantly change/improve traditional manufacturing concepts, due to the need of better understanding and control of the manufacturing processes at the micro/nano-scale as well as due to the new way in which the products could be manufactured. No matter which length scale is to be dealt with, the process development in micro-/nano-manufacturing is of general significance to all length-scales manufacturing for enhanced process capabilities and performances.

- To be able to meet much more stringent requirements in tool-fabrication for micro-/nano-manufacturing will deliver new knowledge and enabling techniques for the whole tool-industry, which will help to improve the traditional tool-industry to meet new challenges and competition, such as that on tooling capability, tool dimensional precision, surface quality and performance.

- New manufacturing machine and system concepts, such as bench-top, miniature, micro-machines, reconfigurable systems and control strategy, will have significant impact on all manufacturing sectors in design, construction and use of the manufacturing machines. Actually, miniaturised machines/systems represent a revolutionary concept for future machine/system designs, including that for manufacturing large-sized parts/components.

\subsection{Business related issues}

Correct assessment of an emerging technology to be utilised with a view to fully understanding the implication and impact on the business is very important. Experience should be learnt from previous cases concerning MEMS manufacturing which saw some companies struggling to survive or disappearing from the business shortly after they actually started. A business built on lower TRL (Technology Readiness Level) is always of a risk.

Micro/Nano-manufacturing may be seen as an expensive business that is characterised by high investment in resources (facilities, knowledge and skills) and often, low volumes. Decision-making on the development or utilisation of the technologies should take these factors into account, together with other technological issues, such as dealing with multi-materials, small geometries, increased and complex functionalities of products.

Completing supply chains for micro-manufacturing-based business is an important issue to be addressed. The micro-manufacturing is often affected by lack of the required raw materials and high-quality tool suppliers as well as auxiliary facilities such as that for inspection and handling. Without completed, efficient and manageable supply chains, a sustainable micro-manufacturing industry cannot be established.

Other difficulties may be encountered, such as insufficient knowledge on the cost implications concerning materials and tooling, lack of advanced MRP systems exclusively for micro-/nano-manufacturing, and lack of standards for emerging manufacturing processes, equipment and tooling. 
The recently funded EU RTD projects had made or have been making effort to address these issues, such as developing high-yield, low-cost manufacturing processes, low-cost equipment; engaging with the whole supply chain when the projects are being executed; and involving end-users in the early stage of the development. Recent EU initiatives on the development of pilot production-lines and manufacturing facility collaborative hubs will certainly help to address the issues raised above and hence, better promote applications of micro/nanomanufacturing research results and drive the development of micro/nano-manufacturing business EU-wide further.

\section{Summary and Outlook of Future Challenges and Opportunities}

The continuing trend of miniaturisation of products, devices and equipment has been a major driver to the development of micro- and nano-manufacturing technology. Compared to the development of 10 years ago, which saw micro-manufacturing research being focused significantly on fundamental issues concerning the scaling down of conventional processes and equipment, recent development has been largely sectorapplications-driven. During the last 10 years, the number of manufacturing processes investigated has increased significantly; manufacturing processes such as micro-machining, laser machining, Micro-EDM, Micro-ECM, hot-embossing, roll-to-roll forming, micro powder injection moulding, photo-electro-forming, have been mature for applications; effort in research and technological development has been shifted significantly to the transforming of the laboratory processes into items of production equipment; and the development has been targeting onto sector-specific applications. In addition to the effort in developing multi-materials processing capabilities, low-cost equipment and pilot production lines, advanced tools and analysis software, high-quality materials and nano-materials, inline inspection, quality assurance, and standardisation, are also being addressed. Life cycle engineering is another field already incorporated into the micro- and nanomanufacturing research and technological development.

The scope of the research and applications of micro-manufacturing has been very wide, according to the sources of reporting. In general, micro-manufacturing may be defined as manufacture that covers:

$\checkmark$ Micro-/nano-precision manufacturing of macro-sized components;

$\checkmark$ Micro/nano-feature manufacturing over small and large areas;

$\checkmark$ Manufacturing of micro-sized components;

$\checkmark$ Manufacturing with micro/nano-structured materials;

$\checkmark$ Manufacturing with controlled micro-structures of materials,

and hence, micro-manufacturing is of a broad significance to industry. It does not necessarily address "small size" products and features only but can also be incorporated into general production steps for various products.

Considering that micro-manufacturing bridges between potential, high-impact nano-science and nanotechnology, and real-world, low-cost products, it will achieve further significant development over the next 10 years. It is most likely that the micro- and nano-manufacturing research will be influenced significantly by the following developments and demands:

- Nanotechnology and sciences have tremendous potentials to positively influence future products and our life, and mostly successful applications, to-date, are probably in the field of nano-materials, coatings, sensors and Nanoelectromechanical systems (NEMS), which has seen applications in almost all sectors. To realise these products, sometimes, could involve high costs and long process chains. A typical example is conversion of nano-structured metals into engineering products which would still need more efficient processes while maintaining low cost. Lack of advanced, low-cost manufacturing technology would continue to hamper widespread applications of such materials. In general, from the nanoscale designs to the real life macro-scale products, there are significant gaps, in terms of efficient and low-cost conversion technologies, which renders challenges as well as opportunities for micro-manufacturing 
research and technological development. Material and manufacturing cost is still a major issue to be addressed sufficiently, in micro- and nano-manufacturing business.

- In the field of transport, especially automobiles, significantly increased uses of sensors, MEMs, microactuators, micro-electronics products have resulted in an increased share of the cost of the automobiles. The effort in reducing cost of manufacturing body-structures, engines and transmission systems will have difficulties to go further since ever-improved mass-production capabilities in metal and composite processing and fabrications already brought the cost done substantially. The effort should now be focused more on how to reduce the manufacturing cost of those "small" parts/products to bring the overall cost of automobiles down. It also means that micro- and nano-manufacturing cannot continue to be an expensive business but meet challenges to bring the manufacturing cost down. Therefore, continuing improving micro- and nano-materials, manufacturing processes and equipment with a view to enabling high-efficient volume production is still required and highly significant.

- In the future, cars consuming petrol and diesel will be further reduced and even totally replaced in an attempt to cut toxic emissions, according to recent moves from the governments. Using battery-powered vehicles is one of the popular solutions. Giving up completely petrol and diesel cars will have huge impact onto manufacturing industries as well as associated supply chains. Designing and manufacturing new cars, vehicles in general, also means uses of new actuating, sensor, charging, control designs, involving, largely, MEMs and micro-electronics manufacturing. Needs for efficient battery and charging technology with low cost offers unlimited challenges and opportunities for micro- and nano-manufacturing research, e.g. challenges and opportunities concerning how to bring the cost of batteries down in order to reduce the overall cost of electric cars. Forming lightweight, nano-structured materials and components for compact cars is another field offering manufacturing research opportunities.

- Micro- and nano-manufacturing can contribute to the development of energy efficient systems more, including new energy systems, addressing both production, conversion, transport, storage and uses. For example, it can further improve efficiency of photovoltaic products by improving optics design and nanostructuring for thermoelectricity conversion; improve fuel-cell designs and manufacturing for better performance; improve materials and structures for heat exchanges, harvesting and insulation. Using nanostructured materials and advanced surface engineering technology for energy-system components for improving system efficiency continues to be attractive technological options. Micro-engine is a promising technological concept that has high potentials. Improving the designs and developing low-cost manufacturing solutions could lead to real, practical applications of micro-engine products.

- The concepts of smart materials and structures have now gone beyond the conventional concepts of multifunction materials and structures, and these, potentially, could offer significant support to the development of true, smart engineering structures, devices and systems. Functionalities such as selfdiagnosis, self-healing, self-repairing, self-sensing and self-actuation, are what being pursued for some critical structures and systems. The number of such materials and structures that are of required reliability, robustness and economic viability is, however, still quite limited. While certain concepts have been proven and demonstrated, largely, at the laboratory level, applications of these materials and structures are hampered by their reliability in engineering environment and by the lack of effective mass-manufacturing means and facilities to convert the materials into engineering products with reasonable volume production capabilities and low-cost. Developing low-cost mass-production micro- and nano-manufacturing capabilities would help the development and applications of smart materials and structures, e.g. capabilities for embedding those materials and structures into the large structures and systems more effectively and efficiently.

- Lightweight structures and components have been one of the main focuses recently in the research especially relating to the transport applications and consumer goods. Reducing $\mathrm{CO} 2$ emission from vehicles is one of the main drivers. Intensive efforts have been made in the field of materials and forming technology (such as Titanium, Magnesium and Aluminium alloys, Carbon fibre/nano-tube reinforced polymer (CNRP), Metal lightweight cellular structures, etc.). This is why high-temperature forming processes attract renewed interests recently. Micro- and nano-manufacturing research can certainly contribute to the processing of these materials and fabrications of those structures. Examples include incorporating nano-materials into joining processes for joining dissimilar materials, developing micro- 
sensors for lightweight structures and systems, embedding micro-circuits into the lightweight structures for smart functionalities, surface micro/nano structuring over the large areas of lightweight materials to achieve advanced aerodynamics performances, desired hydrophobic and optical properties. Again, converting nano-structured materials into engineering products with low-cost is still of significant challenges.

- Autonomous systems have enormous potentials for production applications. These "smart" and "intelligent" machines/systems perform operations based on determining outcomes of the previous operations and by referring to external circumstances for which a series of monitoring and measuring activities are performed. While current efforts in this field have been largely on vehicles and robots, there is little or limited progress in developing "true" autonomous machines for manufacturing which are truly beyond currently used CNC machines and automated production lines. For example, an autonomous manufacturing machine should be able to: check the material properties and geometry of a raw material provided; adjust operation sequences and processing parameters based on self-learning; stop the process, replace tools and restart the machine automatically without human-intervention, if a process/tool has failed in production. These are beyond general meaning of machine control in production. At the same time, the development of such autonomous machines/systems suggests significant demands on MEMs, sensors, micro-optics, and micro-products in general. Requirements on the micro-products/systems would naturally be much higher than that for normal machines and systems.

- Additive manufacturing has been proven to be able to perform scalable manufacturing and hence, produce components at the different length-scales with a same facility, including fabricating micro and miniature components. Recent advances in fabricating ceramics and metal parts have helped to expand its applications and attract many investments and efforts aiming at exploring its technological and commercial potentials. The working principles of additive manufacturing are ideal for fabricating micro-parts and features due to these being based on bottom-up fabricating approaches. 3D Printing is especially attractive for the fabrication with multi-materials and of complex geometries. However, existing 3D printing facilities were, mostly, not designed for high-precision manufacturing purposes, and there are still issues concerning part porosity, low accuracy and poor surface-finish to be addressed, in terms of meeting requirements of micro- and nano-manufacturing. Hybrid manufacturing involving 3D printing, shaping and micro-machining is expected to help to achieve advances in this field, for which extruder designs for 3D printing itself would need more innovative thinking and new designs are expected.

- Continuing to innovate consumer-electronics product designs and manufacture is expected due to high demands and commercial interests. New functions, being thinner and lighter, seem to be a trend for consumer-electronics products for which micro-forming, micro-machining and micro injection moulding technologies will find more applications. Challenges are still on the fabrication of lightweight structures, new materials, smart materials, smaller sizes and features, and high-quality finish, and all these will have to be achieved with lower cost. While micro-machining and micro injection moulding have achieved widespread applications, potentials of micro-forming have not been realised fully, in terms of industrial applications. Characteristics of some micro-forming processes involving large forming forces/pressures indicate difficulties to be encountered for small-scale tooling and handling, and hence, innovations on the process configurations and tool-designs would be needed.

- One of the main barriers that still hamper applications of advanced micro- and nano-manufacturing technologies in industry, especially in traditional manufacturing industries, is the cost of the manufacturing facilities. To-date, some expensive equipment is used mainly in research laboratories. A micro- or nanomanufacturing process relying mainly on the uses of expensive equipment may find limited industrial applications, while some equipment-design itself did not take into account requirements for production uses. Equipment that enables multi-length-scales manufacturing, is of scalable nature, has multi-materials processing capabilities, is easy to be integrated into a production environment, can help to justify the investment for production applications. The research effort may also be made to develop attachments or modules, assisted with robust metrology and control, to enable transform conventional machine-designs or existing industrial machines to ones that are capable of micro- and nano-manufacturing, which could reduce the demands on the investment and the risks involved in the technology acquisition. 
- As new manufacturing concepts/strategies are emerging, such as Digital manufacturing, Industry 4.0, Cloud manufacturing, Smart Manufacturing, etc. the scope of micro- and nano-manufacturing research should also be expanded to include the new concepts and manufacturing strategies that would make micro- and nano-manufacturing enterprises more efficient and profitable. Currently, some key digital-tools for micro- and nano-manufacturing are still in the stage of development, such as modelling addressing lifecycle engineering, multi-scale modelling and evaluations. Process monitoring to assist in rapid response of the machine systems in micro- and nano-manufacturing is of certain challenges, regarding the compact device design, small working-space, high resolution, fast response, as well as avoidance of influences from the external environment. Due to the slow progress in standardisation of processes, tools and equipment as well as product quality-assessment systems, comprehensive and robust knowledge-based production management systems and Manufacturing Execution Systems (MES) for micro- and nanomanufacturing that is scaled down from conventional manufacturing processes are still not fully established yet, and significant effort in this field would still be needed.

\section{Acknowledgement}

Support from the European Commission for conducting the research through FP6 MASMICRO project (NMP2CT-2004-500095), FP7 M3-2S project (NMP3-SL-2008-213600), POLYTUBES project (NMP2-SE-2009229266), ManuCloud project (NMP-2010-ICT-FOF-260142), LoCoLite Project (NMP-2013-SME-7-604240), Micro-FAST (FoF.NMP.2013-608720), Horizon 2020 MMTech project (H2020-MG-2014-633776), Micro-MAN project (H2020-MSCA ETN), SUPERMAT project (H2020-2016-692216), LoCoMaTech Project (H2020-2016723517), and from EPSRC through Micro-3D project (EP/K018345/1) and AUTOMAN project (EP/L505237/1), is acknowledged. Collaborations with all project partners, EU "Factory of the Future" project cluster on micromanufacturing, MINAM and NanoFutures Platform, Royal Society International Exchange Programme with Sichuan University of China, are also acknowledged. The author would also like to thank Professor Frank Travis for his careful proof reading of this paper.

\section{References}

[1] WTEC Panel, International Assessment of Research and Development in Micromanufacturing. October 2005, USA.

[2] European Commission, Downsizing: the march of micro- and nano-manufacture - EU-funded research leads Europe into the world of the ultra-small. 2009, Brussels.

[3] European Micro- and Nanomanufacturing (MINAM) Technology Platform, MINAM Roadmap Reports. 2008 - 2012, 2013.

[4] EU Cordis Project Database, available from: http://cordis.europa.eu/projects/home_en.html

[5] Qin Y, Brockett A, Ma Y, Razali A, Zhao J, Harrison C, Pan W.K, Dai X and Loziak D. Micromanufacturing: research, technology outcomes and development issues. Int J Adv Manuf Tech. 47, 2010, p 821-837.

[6] Qin Y. Micro-Manufacturing Engineering and Technology. Elsevier, 2010 (1st edition) and 2015 (2nd edition), Oxford.

[7] Series articles concerning micro-products and manufacturing, available from: http://www.cmmmagazine.com/

[8] Series articles concerning micro-products and manufacturing, available from http://www.micromanufacturing.com/

[9] Yole Développement. Status of the MEMS Industry 2017, available from: https://www.imicronews.com/report/product/the-status-of-the-mems-industry-2017.html.

[10] Sun X, and Chen K. Multiscale simulation of the nano-metric cutting process. Int. J. Adv. Manuf. Tech., 47, 2010, p 891-901.

[11] Biermann D, Kahleyss F, Krebs $E$ and Upmeier T. A study on micro-machining technology for the machining of NiTi: Five-axis micro-milling and micro deep-hole drilling. J. of Mats Engng. and Performance, 20(4-5), 2011, p 745-751. 
[12] Huo D, Lin C and Dalgarno K. An experimental investigation on micro machining of fine-grained graphite. Int. J. of Adv. Manuf. Tech. 72(5-8), 2014, p 943-953.

[13] Liu J and $\mathrm{Xu} \mathrm{C}$. Interaction of the cutting tools and the ceramic-reinforced metal matrix composites during micro-machining: A review. CIRP J. of Manuf. Sci. and Tech., 7(2), 2014, p 55-70.

[14] Choi S, Lee SM, Hong L, Park JK and Lee DW. Nano/micro machining using multi-arrayed tool for nano/micro surface patterning. Proc. ASPE 2011 Spring Topical Meeting: Structured and Freeform Surfaces, 51, 2011, p 59-62.

[15] McGeough JA. Advanced Methods of Machining, Springer, 1988.

[16] McGeough JA. Micromachining of Engineering Materials. Marcel Dekker, Inc., New York, 2002

[17] Jackson MJ. Micro and Nanomanufacturing, Springer, 2007.

[18] Cheng K and Huo DH. Micro-cutting: Fundamentals and Applications, Wiley, 2013.

[19] Geiger M, Kleiner M, Eckstein R, Tiesler N and Engel U. Micro-forming, Annals of the CIRP, 50/2/2001 p 445 - 462.

[20] Engel U and Geibdorfer S. Microforming technology - on the way to industrial application?, Proc. of the 1 st Int. Conf. on Micro-manufacturing, Urbana-Champaign, USA, Sept. 2006, p 21-30.

[21] Qin Y. Micro-forming and miniature manufacturing systems - Development needs and perspectives, Keynote Paper (plenary address) of the 11th Int. Conf. of Metal Forming, Sept. 2006, J. of Mats. Proc. Tech., 177(1-3), 2006, p 8-18.

[22] Vollertsen F. Size effects in micro forming, Key Engng. Mats., 473, 2011, p 3-12.

[23] Razali A and Qin Y. A review on Micro-manufacturing, Micro-forming and their key issues, Procedia Engineering, 53, 2013, p 665-672.

[24] Fu MW and Chan WL. A review on the state-of-the-art microforming technologies. Int. J. of Adv. Manuf. Tech., 67(9-12), 2013, p 2411-2437.

[25] Hansen HN, Hocken RJ and Tosello G. Replication of micro and nano surface geometries. CIRP Annals, 60/2, 2011, p 695-714.

[26] Worgull M, Kolew A, Heilig M, Schneider M, Dinglreiter H and Rapp B. Hot embossing of high performance polymers, Microsystem Technologies, 17(4), 2011, p 585-592.

[27] Tosello G, Griffiths CA, Dimov SS, Scholz SG, Rees A, Whiteside B and Hansen HN. Analysis of demoulding in micro injection moulding of cyclic-olefin-copolymer microfluidic systems. 4M 2013, San Sebastian, 8-10 October 2013, p 65-68.

[28] Hassanin $\mathrm{H}$ and Jiang K. Net shape manufacturing of ceramic micro parts with tailored graded layers. J. of Micromechanics and Microengineering, 24, 2014, p. 015018 (8 pp.)

[29] Lu D, Yang Y, Qin Y and Yang G. Forming microgears by Micro-FAST technology, J Microelectromech, 22(3), 2013, p 708-715.

[30] Pestarino A, Kueck H, Qin Y, Matteazzi P, Azcarate S, Dickerhof M, Romero P and Qian J. EU FP7 "Factories of the Future" projects to advance micro-manufacturing technology and applications. Int. Co. Micro-Manufacturing Magazine, 8(1), Feb. 2015, p 19-25.

[31] Tang PT. Electroforming: from Rocket Engines to Nanotweezers, J. Micro \& Nanosystems, 3(3), 2011, p 180-187.

[32] Cohen AL. EFAB® Technology: Unlocking the potential of miniaturized medical devices. Available from:http://www.ewp.rpi.edu/hartford/ streej/FWM/Project/References/Microfabrica-

EFAB\%20Technology\%20for\%20Medical\%20Devices.pdf

[33] Ko SH, Chung J, Hotz N, Nam KH and Grigoropoulos CP. Metal nanoparticle direct inkjet printing for low temperature 3D micro metal structure fabrication. J. of Micromechanics and Microengineering, 20, 2010, 125010.

[34] Kullmann C, Hotz N, Schirmer NC, Lee MT, Ko SH, Grigoropoulos CP and Poulikakos D. 3D Microstructures by piezoelectric inkjet printing of gold nanofluids. J. of Micromechanics and Microengineering, 22, 055022, 2012.

[35] Su W, et al. Fully inkjet-printed microfluidics: a solution to low-cost rapid three-dimensional microfluidics fabrication with numerous electrical and sensing applications. Sci. Rep. 6, 35111, 2016.

[36] Vaezi M, Seitz H and Yang SF. A review on 3D micro-additive manufacturing technologies. Int J Adv Manuf Technol, 2013, 67, p 1721-1754. 
[37] Järvenpää E, Heikkilä R, Siltala N, Prusi T and Tuokko R. Micro-factories. in "Micro-manufacturing Engineering and Technology", Qin Y (ed). 2nd Edition, Elsevier, Oxford, May 2015, p 549-580.

[38] http://mikrotools.com/hybriduedm/hybrid-uedm-introduction/, accessed in 2017.

[39] Qin Y, Perzon E, Chronakis I, Calderon I, Konrad K, Hartl C, Holtkamp J, Arentoft M, Larizza P, Zhao J, Hansen KS, Ryll J, Sinisi M, Anyasodor G and Maier F. Process chain and POLYTUBES microfactory concept. the 8th Int. Conf. on Micro-Manufacturing, Victoria, Canada, March 2013, p 211-218.

[40] Qin Y, Zhao J, Anyasodor G, Hansen KS, Calderon I, Konrad K, Hartl C and = Chronakis MIS. Forming of polymeric tubular microcomponents, in "Micro-Manufacturing Engineering and Technology", Qin $Y$ (ed). 2nd Edition, Elsevier, Oxford, 2015, p 179-200.

[41] Tosello G, Hansen HN and Gasparin S. Applications of dimensional micro metrology to the product and process quality control in manufacturing of precision polymer micro components. CIRP Annals Manuf. Tech., 58(1), 2009, p 467-472.

[42] Qian J, Wang J, Ferraris E and Reynaerts D. A holistic approach for zero-defect micro-EDM milling. Proc. of the IEEE Int. Sympo. on Assembly and Manuf., 2013, p 226-229.

[43] Gasparin S, Tosello G, Hansen HN and Islam A. Quality control and process capability assessment for injection-moulded micro mechanical parts, Int. J. of Adv. Manuf. Tech., 66(9-12), 2013, p 1295-1303.

[44] http://cordis.europa.eu/project/rcn/198494_en.html and http://www.microman.mek.dtu.dk/About-us

[45] http://cordis.europa.eu/project/rcn/194305_en.html

[46] Micro-FAST consortium. Bringing the promise of advanced nano-material products closer, thanks to a new process: Micro-FAST - Result In Brief. Available from http://cordis.europa.eu/result/rcn/202463_en.html, 2017.

[47] Zhou Y, Yang Y, Yang G, Yin DG, Qin Y and Liu J. Effects of sintering temperature on the densification of WC-6Co cemented carbides sintered by coupled multi-physical-fields activated technology. Manufacturing Rev. 2015, 2, 18, p 1-5.

[48] Zhou Y, Yang G, Yang Y, Qin Y, Yin DG and Zhang Y. Effect of heating rate on densification and magnetic properties of MnZn ferrites sintered by multiphysical fields coupling methodology, Advances in Applied Ceramics, 113(5), 2014, p 257-261.

[49] Yang XZ, Yang Y, Ynag G, Qin Y and Yin DG. The effect of particle deformation on densification of 316L stainless steel under Micro-FAST. Advanced Materials Research, 939, 2014, p 152-157.

[50] Huang KL, Yang Y, Qin Y, Yang G and Yin DG. A new densification-mechanism of copper powder sintered under an electrical field. Scripta Materialia, 99, 2015, p 85-88.

[51] Huang KL, Yang Y, Qin Y, Yang G and Yin DG. Sintering thermodynamics of fields activated microforming and sintering technology for fabricated $\mathrm{MnZn}$ Ferrite microparts. J. of Microelectromechanical Systems, 3(6), Dec. 2014, p 1389-1395.

[52] Zhao J, Qin Y, Huang KL, Zulkipli MB, and Hijji H. Forming of micro-components by electrical-field activated sintering. MATEC Web of Conferences 21, 10001 (2015), p 1-7.

[53] Huang KL, Qin Y, Zhao J, Zulkipli MB and Hijji H. Fabrication of NiTi shape memory alloy by MicroFAST. MATEC Web of Conferences 21, 10003 (2015), p 1-7.

[54] Zulkipli MB, Qin Y, Huang KL, Hijji H, Zhao YH and Zhao J. Forming of titanium and titanium alloy miniature-cylinders by electrical-field activated powder sintering and forming. MATEC Web of Conferences 21, 10006 (2015), p 1-6.

[55] Hijii H, QIN Y, Huang KL, Zulkipli MB, Yang S and Zhao J. Forming Alumina $\left(\mathrm{Al}_{2} \mathrm{O}_{3}\right)$ by Micro-FAST. Proc. of the 14th Int. Conf. on Manufacturing Research, Loughborough, Sept. 2016, p 61-66. 